\title{
Prevalence of Dental Caries in 5- to 12-Year-Old School Children of Patiala City, Punjab
}

\author{
${ }^{1}$ Pedodontics and Preventive Dentistry, Punjab Government Dental \\ College and Hospital, Amritsar, Punjab, India \\ 2Pediatric and Preventive Dentistry, Bhojia Dental College and \\ Hospital, Baddi, Himachal Pradesh, India
}

Surinder Kaur ${ }^{1}$ Avninder Kaur ${ }^{2}$ Reetu Singh ${ }^{2} \quad$ Avijit Avasthi $^{2} \quad$ Alvi Fatima ${ }^{2}$

Address for correspondence Surinder Kaur, MDS, Pedodontics and Preventive Dentistry, Punjab Government Dental College and Hospital, Amritsar, Punjab 143001, India (e-mail: drsurinder1970@gmail.com).

\author{
Abstract \\ Keywords \\ - dental caries \\ - Punjab \\ - oral hygiene
}

Introduction The present study was conducted with the aim to evaluate prevalence of dental caries in 5- to 12-year-old children in the city of Patiala, Punjab.

Materials and Methods This cross sectional study comprised 1,600 school children belonging to upper middle and lower middle class groups. The children were examined in their schools itself sitting on an ordinary chair.

Results Caries prevalence reported was 40\%. Higher decayed, missing, and filled teeth were found in children eating sweet foods.

Conclusion Results reveal a high percentage of children with dental caries which shows a need for oral health awareness in these children. A low percentage of children was brushing twice a day.

\section{Introduction}

Dental caries is an irreversible microbial disease of the calcified tissues of the teeth which is characterized by demineralization of the inorganic portion and destruction of the organic substance which often leads to cavity formation. ${ }^{1}$ It is prevalent in almost all sections of the society and its trend is increasing with the introduction of refined food in the diet.,3 It is a multifactorial and complex disease with the interplay of three main factors involving host (tooth), oral microflora, and the substrate (diet) with time playing an important role for its input in the carious process. ${ }^{4}$

Dental caries currently represents the most common chronic disease among children. ${ }^{5}$ it is five times more common than asthma, and seven times more common than seasonal allergies. ${ }^{6}$ Dental caries is highly prevalent oral disease which is largely preventable and can be reduced through various health promotion and preventive measures. The increase in prevalence of dental caries is observed parallel to the rapid nutrition transition in the recent decades and may also be one of its consequences. Children of all ages are affected by dental caries. The effectiveness of dental health education will be greatly enhanced if sugar control, sensible use of fluoride, and oral cleanliness to reduce dental caries, are encouraged by all primary health care workers. The vital role of maintaining hygiene in the oral cavity reduces the risk of having carious lesions as these practices remove the necessary substrate in the oral environment needed by the pathogenic oral flora to form acid necessary for the decay process. It becomes imperative to collect the data on prevalence of dental caries as well as the knowledge of the common people about the dietary habits, oral hygiene practices, and the effect of these practices on dental caries.

As there is lack of such data in different districts of Punjab, the present article emphasizes on the prevalence of dental caries in Patiala district of Punjab and its relation to the oral hygiene habits and sugar consumption.

\section{Materials and Methods}

A cross-sectional study was conducted among 5- to 13-year-old school children from private schools of Patiala. A sample of 1,600 children was selected for the study and the children from both the sexes were included in the study. Their carious status was evaluated using $\mathrm{WHO} 1997^{7}$ criteria. The carious lesions at $\mathrm{d}_{2}$ and $\mathrm{d}_{3}$ level were evaluated. The participation of the subjects was voluntary. The children were in their primary, mixed, and permanent dentition. A tooth was considered present in the mouth when any part of it was visible. If a permanent and a primary tooth occupied the same tooth space, the status of the
DOI https://doi.org/ 10.1055/s-0040-1703026 ISSN 2321-1482.
(C2020 Bhojia Dental College and Hospital affiliated to Himachal

Pradesh University
License terms

(요 (1) $\Theta \circledast$ 
permanent tooth only was recorded. The children undergoing any long-term medication or orthodontic treatment were excluded from the study. The study followed the Helsinki guidelines; informed consent was obtained from the parents through the school principals. The clinical examination was done in day light seating the child on an ordinary chair facing away from direct sunlight. The examination was done with mouth mirror and blunt probe where probe was used to remove debris. The children with dental caries were selected and their brushing habits were obtained from children and their parents in the next parent teacher meeting. Their preference for in-between meal snack was also enquired. Data were entered in the proforma by a trained assistant and examination was done by a single examiner. The proforma consisted of tree parts; first part contained sociodemographic information, second part had questions regarding oral hygiene and dietary habits and third and in last part recorded caries experience. $p$-Value of 0.05 was considered statistically significant.

\section{Results}

A total of 1,600 children were selected for the study. Equal distribution of children was taken in each group, that is, 200 children. Forty percent of the children had dental caries, that is, 640 children. The mean age of the sample was $9 \pm 2$ years. Six-year-old children had highest prevalence (52\%) whereas least prevalence, that is, $20 \%$ was shown in 12-year-old. - Table 1 shows the mean decayed, missing, and filled teeth (DMFT/dmft) along with DT/dt, MT/mt, and FT/ $\mathrm{ft}$ of the sample. Once a day brushing was more prevalent,

Table 1 Status of dentition in affected children

\begin{tabular}{|l|l|}
\hline Mean of individual component & Mean \\
\hline $\mathrm{DMFT} / \mathrm{dmft}$ & $3.20 \pm 1.99$ \\
\hline $\mathrm{DT} / \mathrm{dt}$ & $2.20 \pm 1.54$ \\
\hline $\mathrm{MT} / \mathrm{mt}$ & $0.70 \pm 0.87$ \\
\hline $\mathrm{FT} / \mathrm{ft}$ & $0.26 \pm 0.53$ \\
\hline
\end{tabular}

Abbreviations: DMFT, decayed, missing, and filled teeth; DT, decayed teeth; FT, filled teeth; MT, missing teeth. that is, $70.3 \%$ compared with twice a day, that is, $29.4 \%$. Once a week tooth brushing was found in only $0.3 \%$ children. Use of fluoridated tooth paste was higher (53.7\%) compared with nonfluoridated tooth paste (46.3\%). - Table 2 shows the relationship of type of diet with dental caries. - Table $\mathbf{3}$ shows the dentition status according to socioeconomic status.

\section{Discussion}

Dental caries is a disease of modernization and was less prevalent in olden times. Though preventable, it is still increasing due to dietary habits and lack of awareness in general public regarding oral hygiene habits. As dental caries has multifactorial etiology, its prevention is always questionable due to underestimation of preventive factors. A balance is required to maintain between etiological and preventive factors to achieve good oral health.

Many dental caries recording systems have been evolved to diagnose caries at various stages. Many of these systems record the incipient stages of dental caries, which consume a lot of time for recording to be correlated with several factors along with the treatment needs evaluation. In the present study, there was a need for an index which could record dental caries at the cavitation level without consuming much time and widely used and comparable with other national and international studies. Thus WHO $1997^{7}$ criterion was used which is easy to apply in the field studies.

Out of 1,600 children, 640 were having caries, that is, $40 \%$ (-Table 4). A higher prevalence was noted in younger children compared with older children. This could be due to the reason that parents do not give much importance to primary dentition. They think it is temporary and going to replace in a few years. Similar trends were noted by Prabhu et al, ${ }^{8}$ that is, $44.34 \%$ prevalence in 5 -year-old children. The prevalence of dental caries in the 5-year-old children was reported to be $71.1 \%$ in South Kanara by Shetty and Tandon, ${ }^{9} 57.9 \%$ in the city of Cuttack in Orissa by Dash et al ${ }^{10}, 94.3 \%$ in Mangalore city by Sudha et al. ${ }^{11}$

Chawla et $\mathrm{a}^{12}$ in their study reported a prevalence of $60.3 \%$. They attributed the high prevalence of dental caries to the lack of oral hygiene practices, deficient manual dexterity in the early

Table 2 Dietary practices and dental caries (independent t-test)

\begin{tabular}{|l|l|l|l|l|l|}
\hline Type of snack & Frequency & Mean DMFT/dmft & Mean DT/dt & Mean MT/mt & Mean FT/ft \\
\hline Sweet & $362(56.6 \%)$ & $3.34 \pm 2.09$ & $2.35 \pm 1.68$ & $0.67 \pm 0.81$ & $0.28 \pm 0.55$ \\
\hline Salty & $278(43.4 \%)$ & $3.02 \pm 1.83$ & $2.01 \pm 131$ & $0.74 \pm 0.94$ & $0.23 \pm 0.51$ \\
\hline$p$-Value & & 0.04 & 0.006 & 0.3 & 0.3 \\
\hline
\end{tabular}

Abbreviations: DMFT, decayed, missing, and filled teeth; DT, decayed teeth; FT, filled teeth; MT, missing teeth.

Table 3 Correlation of dentition status with socioeconomic status

\begin{tabular}{|l|l|l|l|l|l|}
\hline Socioeconomic status $(N=640)$ & Frequency & Mean DMFT/dmft & DT/dt & MT/mt & FT/ft \\
\hline Upper middle class & $336(52.5 \%)$ & $3.36 \pm 2.09$ & $2.37 \pm 1.67$ & $0.65 \pm 0.83$ & $0.29 \pm 0.57$ \\
\hline Lower middle class & $304(47.5 \%)$ & $3.03 \pm 1.86$ & $2.01 \pm 1.36$ & $0.76 \pm 0.90$ & $0.22 \pm 0.48$ \\
\hline$p$-Value & & 0.03 & 0.004 & 0.11 & 0.11 \\
\hline
\end{tabular}

Abbreviations: DMFT, decayed, missing, and filled teeth; DT, decayed teeth; FT, filled teeth; MT, missing teeth. 
Table 4 Prevalence of dental caries according to age

\begin{tabular}{|c|c|c|c|c|}
\hline Age (y) & $\begin{array}{l}\text { Total } \\
\text { sample } \\
(N=1,600)\end{array}$ & $\begin{array}{l}\text { Affected } \\
\text { with caries } \\
(n=640)\end{array}$ & $\begin{array}{l}\text { Percentage } \\
\text { of affected } \\
\text { children }\end{array}$ & $\begin{array}{l}\text { Mean } \\
\text { age }\end{array}$ \\
\hline 5 & 200 & 99 & $49.5 \%$ & \multirow[t]{8}{*}{$9 \pm 2$} \\
\hline 6 & 200 & 104 & $52 \%$ & \\
\hline 7 & 200 & 80 & $40 \%$ & \\
\hline 8 & 200 & 93 & $46.5 \%$ & \\
\hline 9 & 200 & 84 & $42 \%$ & \\
\hline 10 & 200 & 64 & $32 \%$ & \\
\hline 11 & 200 & 76 & $38 \%$ & \\
\hline 12 & 200 & 40 & $20 \%$ & \\
\hline
\end{tabular}

childhood, and high frequency of consumption of refined carbohydrates. Our findings are consistent with the epidemiological trends from developing countries around the world. Child dental health survey ${ }^{13}$ indicated that there had been no statistically significant changes found between 2003 and 2013 in the proportion of 4- and 8-year old with obvious decay experience. ${ }^{13}$ Dental caries prevalence decreased with increasing age. This might be due to increase in manual dexterity of the children for performing oral hygiene practices. Similar findings have been reported by Goenka et a ${ }^{14}$ in their study on Bihari children and Reddy et $\mathrm{a}^{15}$ in 6 to 12 -year-old children in Telangana.

DMFT/dmft shows a variable range in different age groups. It was $3.20 \pm 1.99$ in our sample where decayed component was highest among the population examined. DT/dt, MT/mt, and FT/ft were $2.20 \pm 1.54,0.70 \pm 0.87$, and $0.26 \pm 0.53$, respectively. DMFT when compared between types of snacks, showed higher in children who eat more sweet foods in-between meals compared with salty food ( $\mathbf{- T a b l e ~} 2$ ). DMFT was compared according to socioeconomic status and was higher in upper middle class compared with lower middle class ( $\mathbf{- T a b l e} \mathbf{3}$ ). Decayed component is higher in all the groups which shows pure lack of awareness among all the children as well as the parents. Carious process if not intervened can lead to pulp exposure and periradicular pathology. The treatment provided will not be simple restorations as in initial lesions, it may lead to pulp therapy or extraction. More decayed teeth reflect more treatment needs in the population examined. Quality of life is also compromised in affected children.

Our study also aimed to evaluate the potential risk factors that determine the level of caries experience. These were socioeconomic status, type of in-between meals snacking, oral hygiene status, and type of toothpaste used. The results show that once a day brushing was more prevalent, that is, $70.3 \%$ compared with twice a day, that is, $29.4 \%$. Once a week tooth brushing was found in only $0.3 \%$ children. Similar results were reported by Prasad et al, ${ }^{16}$ that is, is $30.9 \%$ children brushed their teeth twice a day. A slightly higher frequency, that is, 39.7 and $38.5 \%$ was reported by Prabhakar et $\mathrm{al}^{17}$ and Harikiran et $\mathrm{al}^{18}$ in Chandigarh and Bangalore, respectively. A close look at different studies reveals caries prevalence between 18 and $96 \%$ which is a quite wide range.

\section{Conclusion}

Highest prevalence was found in 6-year-old children, that is, $52 \%$ whereas lowest was found in 12 year old which is $20 \%$. Most of the children were brushing once a day, that is, $70.3 \%$ compared with twice a day, that is, $29.4 \%$. Oral health care awareness is less in children.

\section{Conflict of Interest}

None declared.

\section{References}

1 Rajendran A, Shivapathasundharam B. Shafer's Textbook of Oral Pathology. 5th ed. Noida: Elsevier; 2005

2 Rao A, Sequeira SP, Peter S. Prevalence of dental caries among school children of Moodbidri. J Indian Soc Pedod Prev Dent 1999;17(2):45-48

3 Mahesh Kumar P, Joseph T, Varma RB, Jayanthi M. Oral health status of 5 years and 12 years school going children in Chennai city-an epidemiological study. J Indian Soc Pedod Prev Dent 2005;23(1):17-22

4 Keyes P, Fitzgerald RJ. Dental caries in hamsters induced by transfer of cariogenic plaque. J Dent Res 1961;40:700

5 Oral health in America: Summary of the surgeon's general report. Available at: https://www.nidcr.nih.gov/research/ data-statistics/surgeon-general. Accessed March 3, 2020

6 Edelstein BL, Douglass CW. Dispelling the myth that 50 percent of U.S. schoolchildren have never had a cavity. Public Health Rep 1995;110(5):522-530

7 World Health Organisation. Oral Health Survey. Basic Methods. 4th ed. Geneva: WHO; 1997:39-46

8 Prabhu P, Rajajee KT, Sudheer KA, Jesudass G. Assessment of caries prevalence among children below 5 years old. J Int Soc Prev Community Dent 2014;4(1):40-43

9 Shetty NS, Tandon S. Prevalence of dental caries as related to risk factors in schoolchildren of South Kanara. J Indian Soc Pedod Prev Dent 1988;6(1):30-37

10 Dash JK, Sahoo PK, Bhuyan SK, Sahoo SK. Prevalence of dental caries and treatment needs among children of Cuttack (Orissa). J Indian Soc Pedod Prev Dent 2002;20(4):139-143

11 Sudha P, Bhasin S, Anegundi RT. Prevalence of dental caries among 5-13-year-old children of Mangalore city. J Indian Soc Pedod Prev Dent 2005;23(2):74-79

12 Chawla HS, Gauba K, Goyal A. Trend of dental caries in children of Chandigarh over the last sixteen years. J Indian Soc Pedod Prev Dent 2000;18(1):41-45

13 Ravaghi V, Hill K, Ryan R, Dennes M. Decline in obvious decay in children's permanent teeth. In: Children's Dental Health Survey 2013. Country Specific Report: Northern Ireland. Health and Social Care Information Centre; 2015

14 Goenka P, Dutta S, Marwah N, Sarawgi A, Nirwan M, Mishra P. Prevalence of dental caries in children of age 5 to 13 years in district Vaishali, Bihar, India. Int J Clin Pediatr Dent 2018;11(5):359-364

15 Reddy KS, Reddy S, Ravindhar P, Balaji K, Reddy H, Reddy A. Prevalence of dental caries among 6-12 years school children of Mahbubnagar district, Telangana state, India: a crosssectional study. Indian J Dent Sci 2017;9(1):1-7 
16 Prasad AK, Shankar S, Sowmya J, Priya CV. Oral health knowledge, attitude and practice of school students of KSR Matriculation School, Tiruchengode. J Indian Acad Dent Spec 2010;1:5-10

17 Prabhakar J, John J, Srisakthi D. Prevalence of dental caries and treatment needs among school going children of Chandigarh. Indian J Dent Res 2016;169:547-552
18 Harikiran AG, Pallavi SK, Hariprakash S, Nagesh KS; Ashutosh. Oral health-related KAP among 11- to 12-year-old school children in a government-aided missionary school of Bangalore city. Indian J Dent Res 2008;19(3):236-242 